\title{
Selecting parameter values for the AWBM daily rainfall-runoff model for use on ungauged catchments \\ by \\ Walter Boughton ${ }^{1}$
}

\begin{abstract}
A new method of calibration of the Australian Water Balance Model (AWBM) daily rainfall-runoff model allows for errors in the estimation of areal rainfall over the catchment. The result of applying the method to a group of gauged catchments is the production of a single set of parameter values for the AWBM that can be used with any catchment in the group, or used to estimate runoff on ungauged catchments in the same locality. The method is demonstrated on 121 catchments, comprising groups in five States of Australia from the tropics to temperate zones and over a wide range of catchment sizes and runoff characteristics. With adjustments to input rainfall of less than $20 \%$, the average annual runoff from any catchment in a group can be reproduced by a single set of parameter values to any required degree of precision. The ability of a single set of parameter values to estimate average annual runoff from a group of catchments with only small adjustments of input rainfall raises doubts about the ability to determine the effects of catchment characteristics on runoff with current rainfall-runoff data sets.
\end{abstract}

\section{INTRODUCTION}

Since the 1960s, computer modelling of the water balance of catchments has been the major technique for relating runoff to rainfall at catchment scale - see reviews by Singh and Woolhiser (2002) and Boughton (2005). Where streamflow data have been available for calibration of model parameters, the water balance models have been very successful. However, there has been little success in the use of the models for estimating runoff on ungauged catchments. The recent Prediction in Ungauged Basins (PUB) and the Model Parameter Estimation Experiment (MOPEX) international programs have concentrated multi-national effort on the problem. See:

http://cee.uiuc.edu/research/pub $\quad$ (PUB)

http://www.nws.noaa.gov/oh/mopex $\quad$ (MOPEX)

In order to use a rainfall-runoff model on an ungauged catchment, the values of model parameters must be estimated from values where the model has been calibrated on gauged catchments. The transfer of parameter values from gauged to ungauged catchments is referred to as regionalization (Blöschl and Sivapalan 1995). There are two methods of transferring parameter values that have been reported in the literature - transferring parameter sets directly from nearby catchments (assuming spatial uniformity); and relating model parameters to catchment characteristics.

\footnotetext{
${ }^{1}$ Honorary Professor, Griffith University, Brisbane, Australia

Post: 11 Preston Place, Brookfield, Qld. 4069, Australia

Email: wboughto@,bigpond.net.au

Tel.: +61733744785
} 
The use of spatial proximity to transfer parameter values can vary from the simple to the complex. Boughton and Chiew (2003) calibrated the AWBM on rainfall and runoff data from 331 catchments, $50-2000 \mathrm{~km}^{2}$ in area, and documented the calibrated parameter values. They recommended that anyone with interest in an ungauged catchment select parameter values for the AWBM from the nearest catchments in the documented list, i.e. a very simple transfer of parameter values (the data sets used in the present study were part of that study). By comparison, Nathan and McMahon (1990) selected groups of catchments for transfer of parameter values by statistical tools such as cluster analysis, principal component analysis and multiple regression. Other studies directed towards delineating homogeneous regions are Merz et al (1999), Yu and Yang (2000) and Merz and Blöschl (2004).

By far, the majority of studies directed to use of a rainfall-runoff model on ungauged catchments have tried to relate parameter values to catchment characteristics (see reviews by Bates, 1994; Blöschl and Sivapalan, 1995; and Merz et al, 2006). The attraction of this method is that proximity to the ungauged catchment is irrelevant, so a much larger group of rainfall-runoff data sets can be used to establish the relationships. The methods vary widely from statistical methods used to group the catchments (Nathan and McMahon, 1990; Bates 1994) to regression relationships (Sefton and Howarth 1998; Seibert 1999; Kokkonen et al 2003; Merz and Blöschl 2004). After their extensive review, Merz et al (2006) concluded "All the studies examined here reported relatively low correlations between model parameters and catchment attributes".

One significant aspect of technology has been the increasing capacity of personal computers to store and process large amounts of rainfall-runoff data. This prompted the organizers of the MOPEX program to organize a collation of regionalization studies based on large samples of data sets (Andréassian et al 2006). The 4 review papers, 18 technical papers and 6 introduction and summary papers give a recent and extensive cover of how the ability to handle large numbers of rainfall-runoff data sets has contributed to modelling capabilities.

It has been demonstrated for some time (Boughton 1996, 2006) that errors in the estimation of areal rainfall can have a big effect on the calibrated values of rainfallrunoff models. It is a common adage that any of the modern rainfall-runoff models will give good results if given good quality data, but none will give good results with poor quality data. In other words, the results from rainfall-runoff modelling depend more on the quality of the input data than on the model. If the estimate of areal catchment rainfall is higher than the true value, this can be compensated by calibrating a higher value for the surface storage parameters such that more rainfall is held for evaporation loss and so reduce calculated runoff (Boughton 2006). The problem of estimating areal rainfall on catchments of a few hundred to a few thousand square kilometers is the main factor affecting the quality of rainfall-runoff modelling.

Two studies have shown that problems created by errors in the estimation of areal rainfall can have a major effect on rainfall-runoff modelling. Nathan and McMahon (1990) calibrated the SFB model on 168 catchments, $1-250 \mathrm{~km}^{2}$ in area, to study the potential of the model for use on ungauged catchments. They found that the model was robust and simple to use, but, on $37 \%$ of the catchments, the rainfall data were not representative of catchment rainfall and satisfactory calibration could not be 
achieved. Boughton and Chiew (2003) calibrated the AWBM on 331 rainfall-runoff data sets and found that input data quality prevented satisfactory calibration on onethird of the catchments. Reports of problems with rainfall data are still appearing in the literature (McIntyre and Al-Qurashi, 2009; Haydon and Delectic, 2009).

Despite the evidence over many years of how errors in the estimation of areal rainfall can affect calibrated values of parameters in rainfall-runoff models, there have been few studies directed towards offsetting those effects. Recently, an approach was suggested as to how the AWBM could be calibrated with specific allowance for possible errors in estimates of areal rainfall (Boughton 2009). This paper extends that study and shows how calibration of a group of gauged catchments with allowance for errors in input rainfalls can produce a single set of parameter values for the AWBM for use on ungauged catchments. The method is demonstrated on groups of catchments in five States of Australia, and shows how sub-sets differ among a large group of catchments.

\section{DATA}

The 121 sets of rainfall and runoff data used in this study were originally part of a larger collation of 331 data sets that were prepared for the National Land and Water Audit of Australia (Peel et al 2001, Chiew et al 2002). The rainfall and climate data are described in Jeffrey et al (2001), and further details can be seen in:

\section{$\underline{\text { http://www.dnr.qld.gov.au/silo }}$}

The data have been used in a number of prior studies (see Boughton 2009). Boughton and Chiew $(2003,2007)$ selected 221 data sets of the better quality data for study. The present selection of 121 data sets are drawn from those better quality data. The catchments are located in the more populated and important agricultural regions of Australia. All catchments are predominantly rural with minimal urban sub-areas. There are 18 catchments in Queensland, 70 in New South Wales, 15 in Tasmania, 8 in South Australia and 10 in Western Australia. The spread from tropical Queensland to temperate Tasmania and from the east coast to the coast of Western Australia covers a very wide range of climates and topography. The ranges in area and annual rainfall are shown in Table 1. The rainfall data were of different lengths and different periods, using the maximum amount of data that were readily available for each catchment.

Table 1 Details of catchments used in study

\begin{tabular}{|c|c|c|c|c|c|}
\hline \multirow{2}{*}{ State } & \multirow{2}{*}{ No } & \multicolumn{2}{|c|}{ Area $\mathbf{~ k m}^{2}$} & \multicolumn{2}{c|}{ Rain $\mathbf{m m} / \mathbf{y r}$} \\
\cline { 3 - 6 } & & Min & Max & Min & Max \\
\hline New South Wales & 70 & 51 & 1870 & 583 & 2289 \\
\hline Queensland & 18 & 78 & 1735 & 697 & 2886 \\
\hline South Australia & 8 & 77 & 828 & 487 & 820 \\
\hline Tasmania & 15 & 53 & 1012 & 546 & 2445 \\
\hline Western Australia & 10 & 102 & 1610 & 390 & 1052 \\
\hline
\end{tabular}




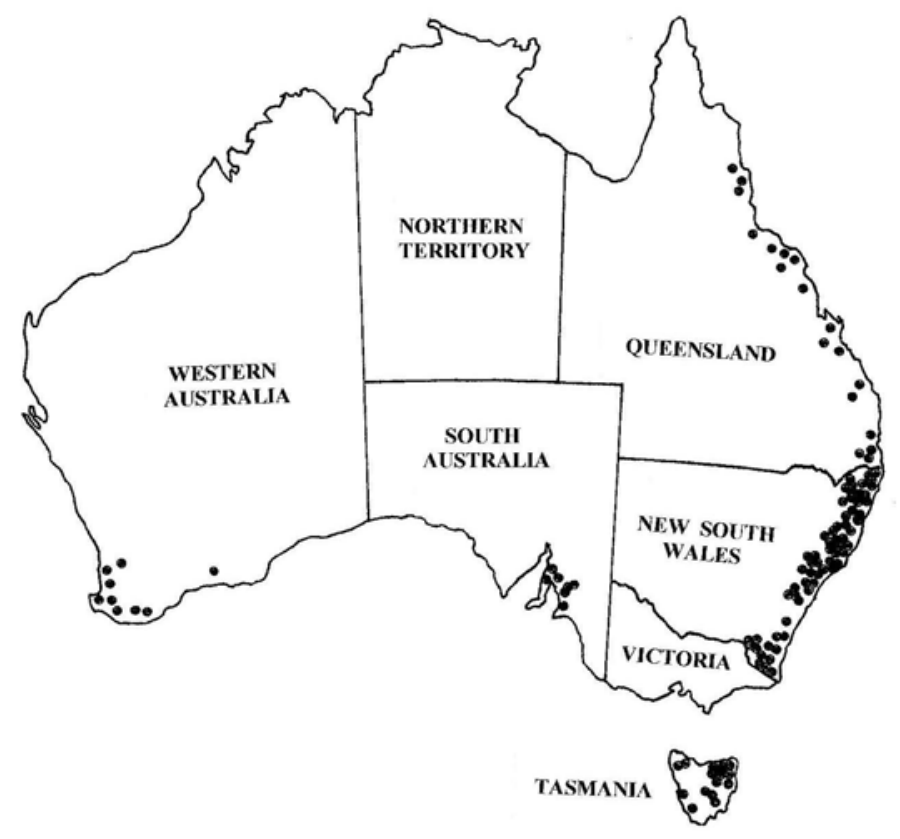

Figure 1 Location of catchments

\section{THE AUSTRALIAN WATER BALANCE MODEL (AWBM) MODEL}

\section{Structure of the AWBM}

The daily rainfall-runoff model used in this study is the AWBM (Boughton 2004). The model calculates runoff as saturation excess from three surface stores of different capacities. This allows for partial area runoff at different times from different parts of the catchment during a storm. The structure of the model is shown in Figure 2.

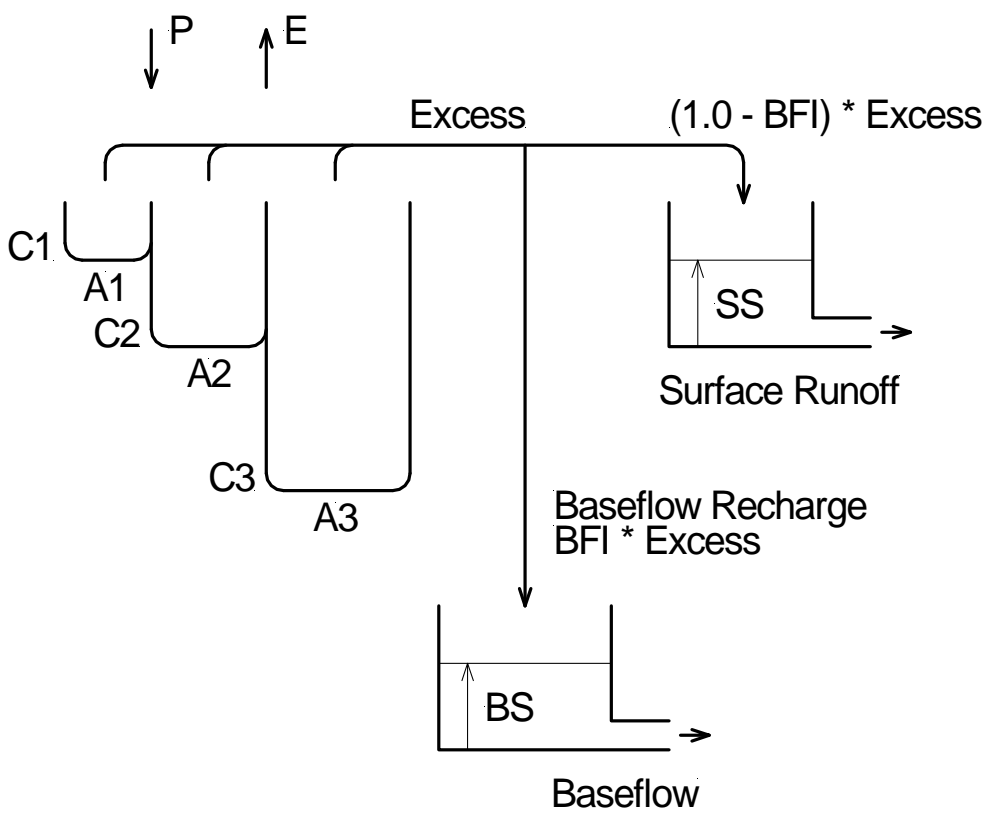

Figure 2 Structure of the AWBM rainfall-runoff model 
There are three surface storage capacities $\mathrm{C} 1, \mathrm{C} 2$ and $\mathrm{C} 3$ that occupy partial areas of the catchment $\mathrm{A} 1, \mathrm{~A} 2$ and $\mathrm{A} 3$ respectively $(\mathrm{A} 1+\mathrm{A} 2+\mathrm{A} 3=1.0)$. The average surface storage capacity is the sum of the three products of capacity and partial area, i.e. $\mathrm{C} 1 * \mathrm{~A} 1+\mathrm{C} 2 * \mathrm{~A} 2+\mathrm{C} 3 * \mathrm{~A} 3$. The average surface storage capacity is the single parameter determining the amount of runoff. This single parameter is disaggregated into a set of capacities and partial areas using a fixed pattern (see Boughton 2004). The term "average" led to some confusion in the review of the paper - confusion with an average from calibrations on different catchments. To avoid confusion, the term "surface storage capacity" in used in this paper to indicate the sum of the three products of capacity and partial area on a single catchment.

The runoff generated as excess from the surface stores is divided into surface runoff and baseflow recharge by the baseflow index (BFI). The discharge from baseflow storage each day is governed by the baseflow recession constant $\left(\mathrm{K}_{\text {base }}\right)$ and calculated as $\left(1.0-\mathrm{K}_{\text {base }}\right)$ times the amount in baseflow store (BS). The discharge from the surface runoff store is calculated as $\left(1.0-\mathrm{K}_{\mathrm{s}}\right)$ times the amount in the store (SS) where $\mathrm{K}_{\mathrm{s}}$ is the daily surface runoff recession constant.

\section{Potential evapotranspiration}

Boughton (2006) used scaling of input data, both rainfall and potential evapotranspiration, to improve the modelling of 68 daily rainfall-runoff data sets that were previously classed as poor quality data. Scaling involved multiplying each daily data by an adjustment factor that was varied by trial and error to find the best modelling result. Rainfall and potential evapotranspiration were varied independently in that study.

The 68 adjustment factors for rainfall varied from 1.50 to 0.65 with an average of 1.02 , indicating a near even spread of factors to either increase or decrease the rainfall. The 68 adjustment factors for potential evapotranspiration varied from 1.25 to 0.65 with an average of 0.86 , i.e. there were significantly more adjustments to decrease than to increase evapotranspiration data. A more recent study (Boughton 2009), using 18 catchments in Queensland, found the average adjustment factor for evapotranspiration was 0.83 . The writer, who developed the AWBM in the early $1990 \mathrm{~s}$, has also found that an adjustment factor of 0.85 for potential evapotranspiration has improved modelling in many individual studies with this model.

The trial and error method of varying rainfall and evapotranspiration showed that many combinations of the two adjustment factors gave similar results. An increase in rainfall could be compensated by an increase in evapotranspiration. For the present study, it was decided to fix the adjustment factor for the 12 monthly values of potential evapotranspiration as 0.85 , and then determine the less complicated factor for rainfall alone. The adjustment factor of 0.85 is related to the AWBM and not to other models. There is no reduction in the value of potential evapotranspiration in any of the three stores in the AWBM as moisture is reduced. Loss of water continues at the potential rate in any store that contains water, and then reduces to zero over the partial area of that store when the store is empty. 


\section{Calibration of the AWBM}

Boughton $(2004,2009)$ reviews the development of model specific methods of calibration of the AWBM based on model structure that are different from the more common method of trial and error search among multiple sets of parameter values using mathematical optimizing techniques. The main development reported in Boughton (2009) is the allowance for error in the estimation of areal rainfall, which has a major impact on the calibration on the runoff generating parameter. The present study extends that allowance for error in areal rainfall into a systematic procedure for developing a single set of parameter values of the AWBM from a group of rainfall and runoff data sets. The new procedure is illustrated in the next section using the Queensland data.

\section{METHOD}

\section{Surface storage capacity}

The aim of the study is to find a single set of parameter values for the AWBM that can be used on a group of catchments, and on ungauged catchments in the same locality as the group. The only AWBM parameter that affects the amount of modeled runoff from a given data set is the surface storage capacity, so the main part of the method is to find a value for that parameter that gives best results over the group. The other two parameters in the model affect only the timing of runoff.

Direct calibration of the surface storage capacity can be substantially affected by small errors in the estimation of areal rainfall that is used as input data. Boughton (1996) demonstrated the magnitude of the effect using data from the $3120 \mathrm{~km}^{2}$ Mary River catchment in south east Queensland. Direct calibration of the AWBM to the original data gave a surface storage capacity of $140 \mathrm{~mm}$, with a coefficient of determination $\left(\mathrm{r}^{2}\right)$ from the regression of observed and modeled monthly totals of runoff of 0.986 . However, changes of only $\pm 10 \%$ in the rainfall data produced changes of $+49 \%$ and $-32 \%$ in the calibrated value of the surface storage capacity. Table 2 shows how the calibrated value of surface storage capacity changes as rainfall is scaled from 0.6 to 1.4 of observed rainfall. The $\mathrm{r}^{2}$ values change much less than the surface storage capacity and have low sensitivity for selecting the best adjustment of rainfall.

Scaling of the rainfall data involved multiplying each daily value by the rainfall adjustment factor Rf. The computer code for the AWBM includes provision for setting adjustment factors to study the effects of errors in input data. If a value of surface storage capacity is assumed for a given data set, the rainfall data can be scaled up or down by trial and error to find the value of $\mathrm{Rf}$ that produces the required surface storage capacity as illustrated in Table 2.

Table 2 Effect of change in catchment rainfall on calibrated value of surface storage capacity (from Boughton 1996)

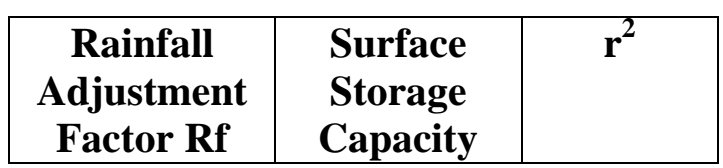




\begin{tabular}{|c|c|c|}
\hline & $\mathbf{m m}$ & \\
\hline 0.6 & 7 & 0.892 \\
\hline 0.8 & 59 & 0.960 \\
\hline 1.0 & 140 & 0.986 \\
\hline 1.2 & 277 & 0.981 \\
\hline 1.4 & 478 & 0.949 \\
\hline
\end{tabular}

To find a value of surface storage capacity for use with a group of catchments (and ungauged catchments in the same region), it is necessary to assume a value of the capacity and then determine the distribution of rainfall adjustment factors $\mathrm{Rf}$ that are required to produce that capacity on each catchment. This is illustrated using a group of 18 catchments on the coast of Queensland. In the first instance, a value of $150 \mathrm{~mm}$ was assumed based on prior experience with the AWBM (Boughton, 2009). With each data set, the rainfall adjustment factor $\mathrm{Rf}$ was varied until the calibrated capacity was $150 \mathrm{~mm}$.

For this assumed value of $150 \mathrm{~mm}$ capacity, there were 4 of the values of Rf that were $>1.0$ (increase of rainfall) and 14 values that were $<1.0$ (decrease of rainfall). The bias towards decrease of rainfall suggested that the assumed capacity of $150 \mathrm{~mm}$ was too small. So larger values were tested and the distribution of rainfall adjustment factors was collated for each capacity. Table 3 shows that, as the assumed value of surface storage capacity increases, the distribution of $\mathrm{Rf}$ values tends to more equal numbers greater than and less than 1.0. When the assumed value was $190 \mathrm{~mm}$, there were 9 values $>1.0$ and 9 values $<1.0$ with an average value of $\mathrm{Rf}$ of 1.0, i.e. the $\mathrm{Rf}$ values were normalized around a mean of 1.0. This approach provides a means of allowing for systematic errors in the estimation of areal rainfall in the determination of a single value of surface storage capacity that can be used on ungauged catchments in the region of a group of gauged catchments.

Table 3 Distribution of rainfall adjustment factors $R f$ with change in selected surface storage capacity

\begin{tabular}{|c|c|c|c|}
\hline \multirow{2}{*}{$\begin{array}{c}\text { Selected } \\
\text { Capacity mm }\end{array}$} & \multicolumn{2}{|c|}{ No of Rf values } & Average \\
\cline { 2 - 3 } Rf
\end{tabular}

There were other indicators to support a surface storage capacity of $190 \mathrm{~mm}$. Fourteen of the 18 adjustment factors for rainfall were within $\pm 10 \%$ of $1.0,16$ were within \pm $15 \%$, and all were within $\pm 20 \%$. The average coefficient of efficiency between observed and modeled monthly totals of runoff was 0.90 from the 18 catchments, indicating good modelling results.

\section{Single set of parameter values}


There are only three parameters in the AWBM, and one (surface storage capacity) was determined to be $190 \mathrm{~mm}$, leaving only the two baseflow parameters (BFI and $\mathrm{K}_{\text {base }}$ ) to be determined. The averages of these parameters among the 18 catchments were BFI $=0.23$ and $\mathrm{K}_{\text {base }}=0.919$, giving a single set of parameters with $190 \mathrm{~mm}$ for the surface storage capacity. This set of parameters was then used to estimate runoff from the 18 catchments, using the adjustments of the rainfall that were found to give the surface storage capacity of $190 \mathrm{~mm}$. Figure 3 shows a comparison of observed and modeled average runoff.

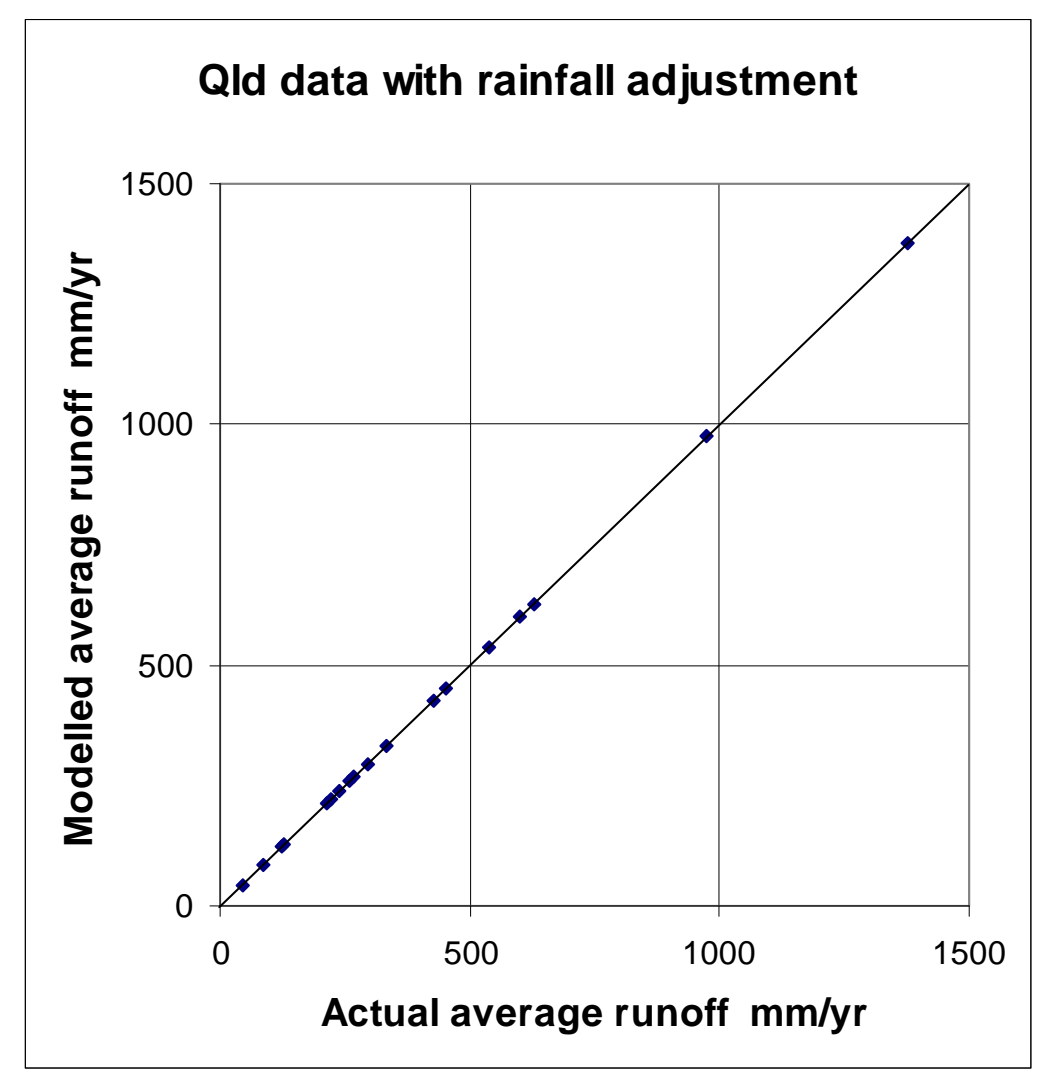

Figure 3 Comparison of observed and modeled average runoff using a single set of parameter values.

Care was taken in adjusting the rainfall data with values of the rainfall adjustment factor (Rf) taken to three decimal places. The results are evident in Figure 3 with negligible differences between observed and calculated runoff for the 18 catchments when the rainfall adjustments were used in calculation. Some $78 \%$ of the rainfall adjustments were $< \pm 10 \%$ and all of the adjustments were $< \pm 20 \%$.

The above clearly shows the big effect that can be produced by error in estimating catchment rainfall. A second test was made using the single set of parameter values but also using the original unadjusted estimates of rainfall. Runoff was calculated for each of the 18 catchments using the single set of parameter values and the original rainfall input data. The results are shown in Figure 4. The coefficient of determination $\left(\mathrm{r}^{2}\right)$ for these results is 0.885 and the coefficient of efficiency is also 0.885 . The mean error of estimation of average annual runoff is $18.7 \%$. 


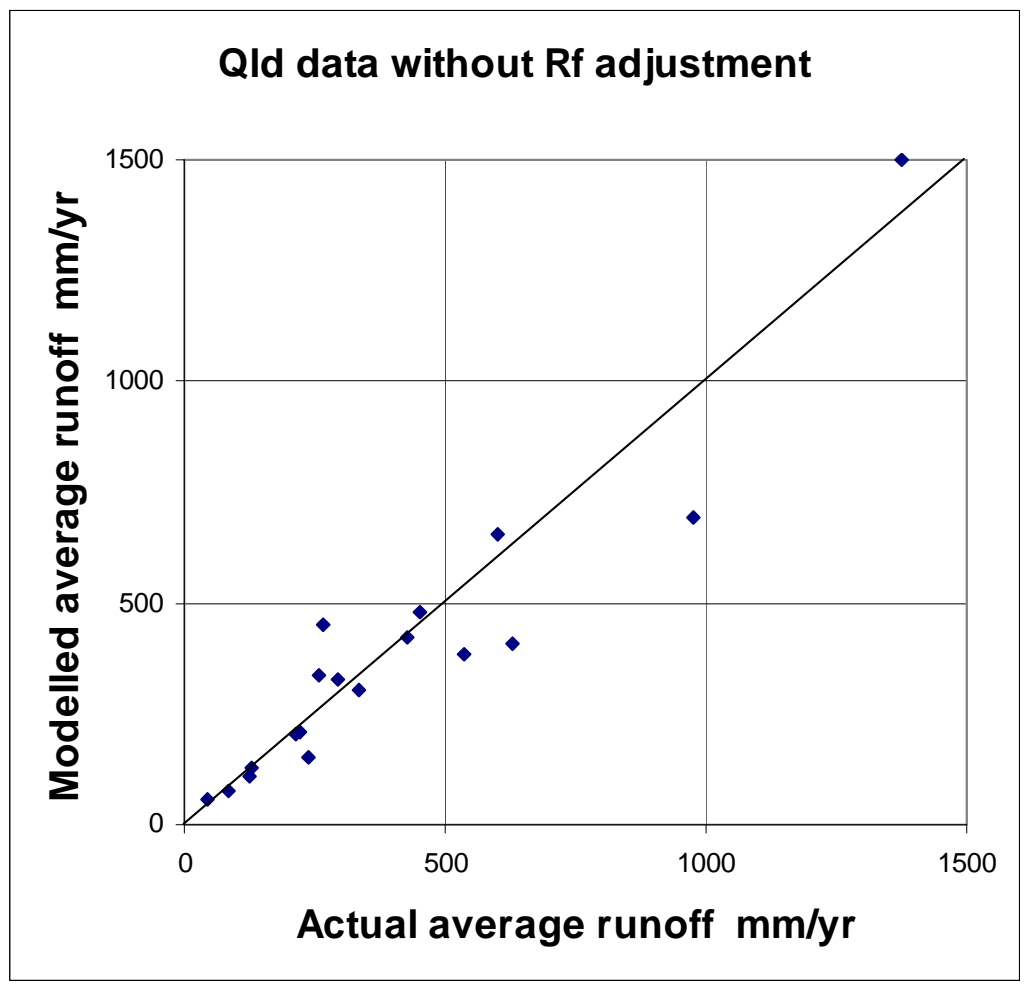

Figure 4 Comparison of observed and modeled runoff without adjustment of rainfall

The wider spread of errors in estimation of runoff is visually evident in Figure 4, but the results are noteworthy that a single set of parameter values can estimate runoff on such a wide spread of catchments over $1000 \mathrm{~km}$ of the Queensland coast. The maximum range of error is now $40 \%$ instead of $20 \%$. About two thirds of the results are now within $\pm 20 \%$, and 15 out of 18 are within $\pm 30 \%$. The major significance is that a single set of parameter values can produce the results without consideration of differences in catchment characteristics.

\section{RESULTS}

\section{Other regions}

The approach of normalizing the spread of rainfall adjustment factors around a mean of 1.0 as demonstrated with the Queensland data was applied to groups of catchments in four other States of Australia, i.e. in New South Wales, South Australia, Tasmania and Western Australia. In each case, an adjustment factor of 0.85 was applied to potential evapotranspiration. The surface storage capacity (which is the single parameter affecting runoff) was determined in each group of catchments, and the results are shown in Table 4. The values of BFI and Kbase shown in Table 4 are average values from the catchments in each State. The three parameters of surface storage capacity, baseflow index and baseflow recession constant are a set of parameter values for use on ungauged catchments. 
Table 4 Average sets of AWBM parameter values in 5 States

\begin{tabular}{|c|c|c|c|c|}
\hline State & $\begin{array}{c}\text { Number of } \\
\text { Catchments }\end{array}$ & $\begin{array}{c}\text { Surface } \\
\text { Storage } \\
\text { Capacity mm }\end{array}$ & $\begin{array}{c}\text { Baseflow } \\
\text { Index } \\
\text { (BFI) }\end{array}$ & $\begin{array}{c}\text { Baseflow } \\
\text { Recession } \\
\text { Constant } \\
\text { K}_{\text {base }}\end{array}$ \\
\hline New South Wales & 70 & 145 & 0.33 & 0.980 \\
\hline Queensland & 18 & 190 & 0.17 & 0.950 \\
\hline South Australia & 8 & 320 & 0.29 & 0.958 \\
\hline Tasmania & 15 & 140 & 0.32 & 0.966 \\
\hline Western Australia & 10 & 410 & 0.56 & 0.956 \\
\hline
\end{tabular}

A comparison of recorded and modeled runoff in Queensland has been shown above. A comparison of runoff in New South Wales is shown in the following section. The results from Tasmania, South Australia and Western Australia are shown in Figures 5 and 6. The average sets of parameter values for Tasmania, South Australia and Western Australia were used to calculate runoff for each catchment in the relevant State. Figures 5 and 6 each show a comparison of recorded and modeled runoff on each catchment in the data sets with rainfall adjustment in Figure 5 and without rainfall adjustment in Figure 6. The coefficient of determination $\left(\mathrm{r}^{2}\right)$ for the results in Figure 6 is 0.974 and the coefficient of efficiency is 0.968 . The mean error of estimation of average annual runoff is $23.2 \%$.

The surface storage capacity is the sole runoff generating parameter, so its variation from $140 \mathrm{~mm}$ in Tasmania to $410 \mathrm{~mm}$ in Western Australia is of particular interest. One obvious association is that regions with a higher average annual runoff have a lower surface storage capacity. The average annual runoff among all catchments in a group is 681, 400, 267, 102 and $45 \mathrm{~mm}$ in Tasmania, Queensland, New South Wales, Western Australia and South Australia respectively. Figure 7 shows these averages and the surface storage capacity for each group of catchments. There is a definite trend towards smaller surface storage capacity with larger average annual runoff, but the spread among the few values is wide and precludes establishing a definite relationship.

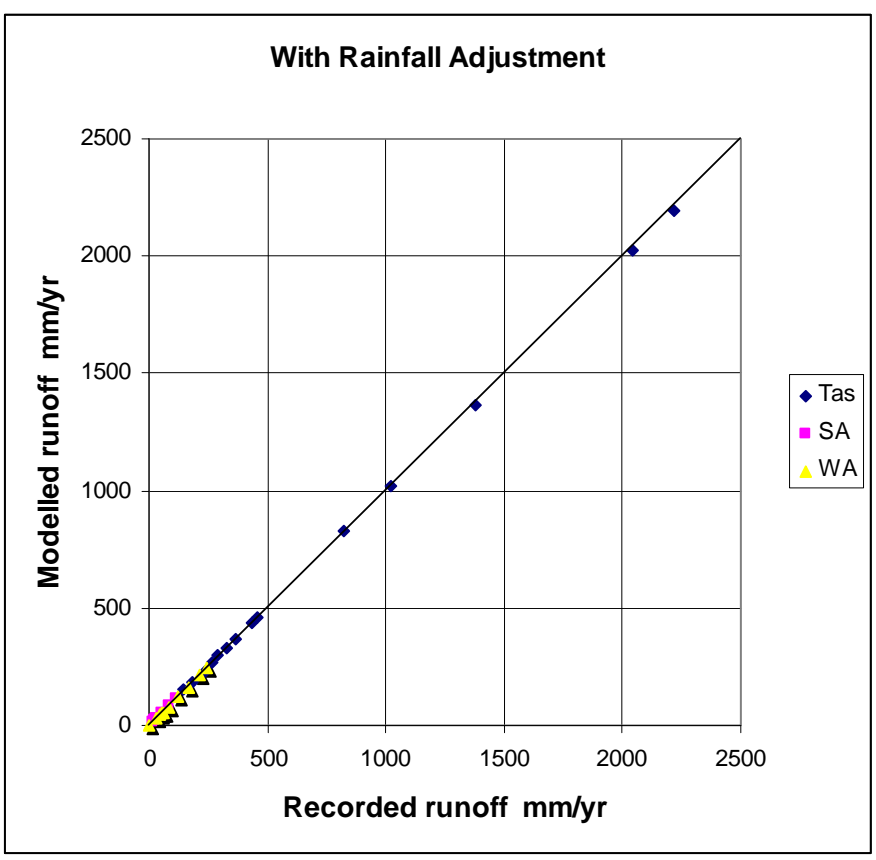


Figure 5 Comparison of observed and modeled runoff on 3 groups of catchment in Tasmania, South Australia and Western Australia with adjustment of rainfalls

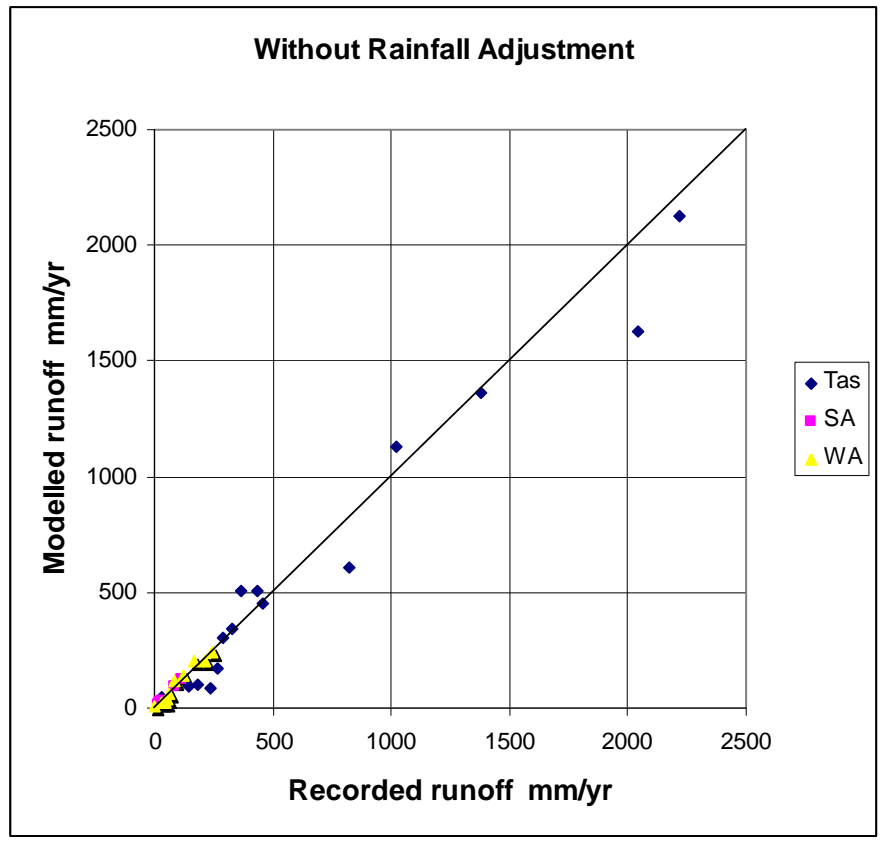

Figure 6 Comparison of observed and modeled runoff in 3 groups of catchments in Tasmania, South Australia and Western Australia - no adjustment of rainfall.

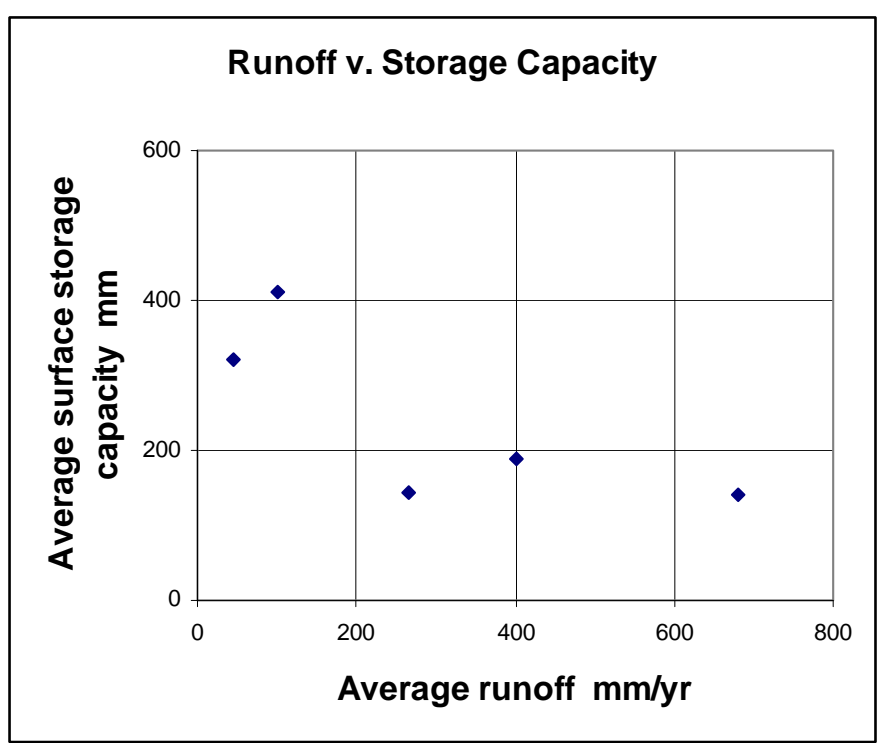

Figure $7 \quad$ Surface storage capacities versus average annual runoff

New South Wales data 
The 70 data sets in coastal New South Wales were calibrated to a surface storage capacity of $145 \mathrm{~mm}$ - see Table 4 . The calibration was based on finding the capacity that best normalized the rainfall adjustment factors Rf. Figure 8 shows the distribution of Rf values for a capacity of $145 \mathrm{~mm}$, and the normalizing of the values can be clearly seen. Sixty-five of the 70 rainfall adjustments (93\%) were in the range $\pm 15 \%$ and all of the values were within the range $\pm 25 \%$.

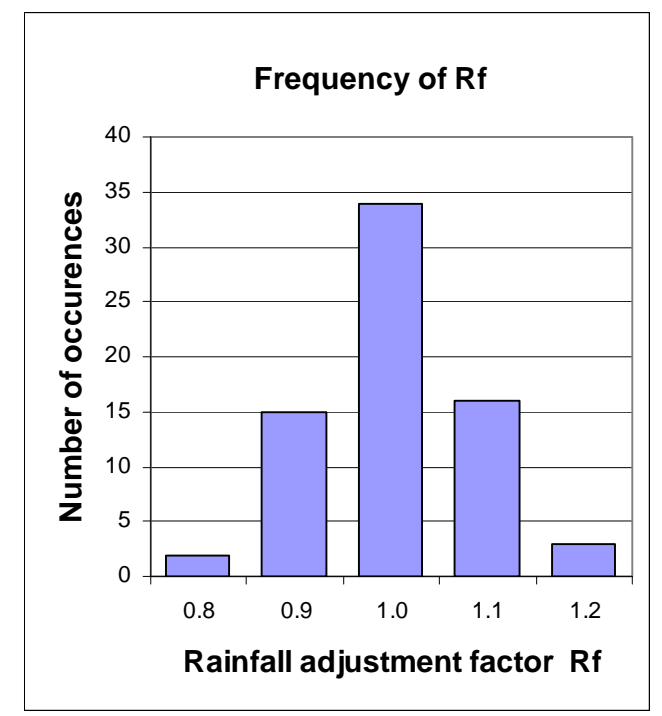

Figure 8 Distribution of $\mathrm{Rf}$ for 70 New South Wales catchments with surface storage capacity of $145 \mathrm{~mm}$

The average set of parameter values for New South Wales catchments shown in Table 4 were used with the rainfall adjustment factors shown in Figure 8 to estimate runoff from each of the 70 catchments. The results are shown in Figure 9. With the small adjustments of rainfall, the amount of runoff on each catchment can be estimated almost exactly with a single set of parameter values. 


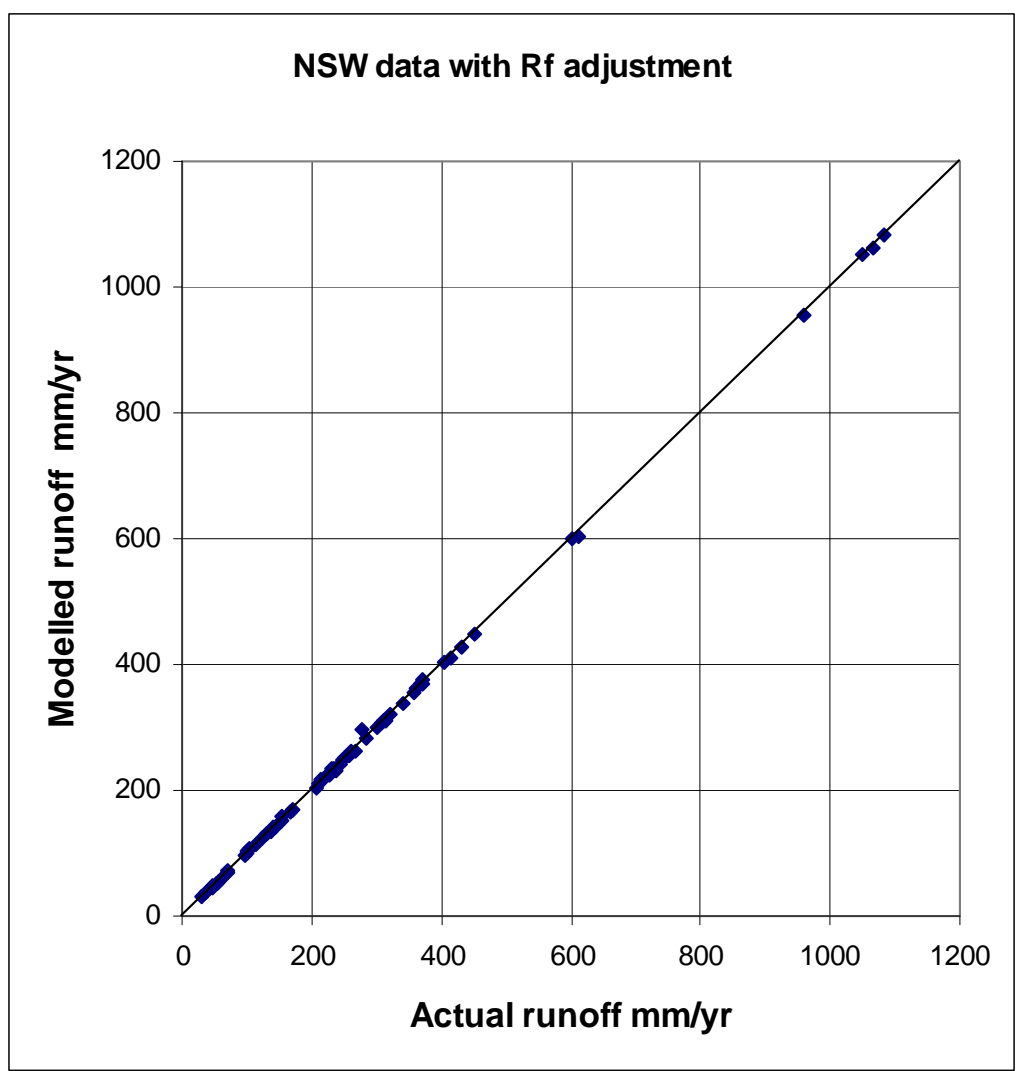

Figure 9 Comparison of observed and modeled runoff on 70 catchments in New South Wales with rainfall adjustments

With adjustments of rainfall of less than $15 \%$, the amount of runoff on 65 of the 70 catchments in coastal New South Wales (93\%) can be estimated with the AWBM and a single set of parameter values to any desired level of precision. The level of precision is determined by how precisely the rainfall adjustment is determined to match the calibrated surface storage capacity to that in the single set of parameter values (145 mm for the coastal New South Wales catchments). The New South Wales catchments are spread over $1000 \mathrm{~km}$ along the coast from the Queensland border in the north to the Victorian border in the south. They encompass a wide range of climates, topography, rainfalls and catchment characteristics.

The single set of parameter values was also used on each of the 70 catchments without any adjustment of rainfall to estimate runoff. A comparison of estimated and observed runoff is shown in Figure 10. The coefficient of determination $\left(\mathrm{r}^{2}\right)$ for these results is 0.883 and the coefficient of efficiency is 0.881 . The mean error of estimation of average annual runoff is $19.8 \%$. 


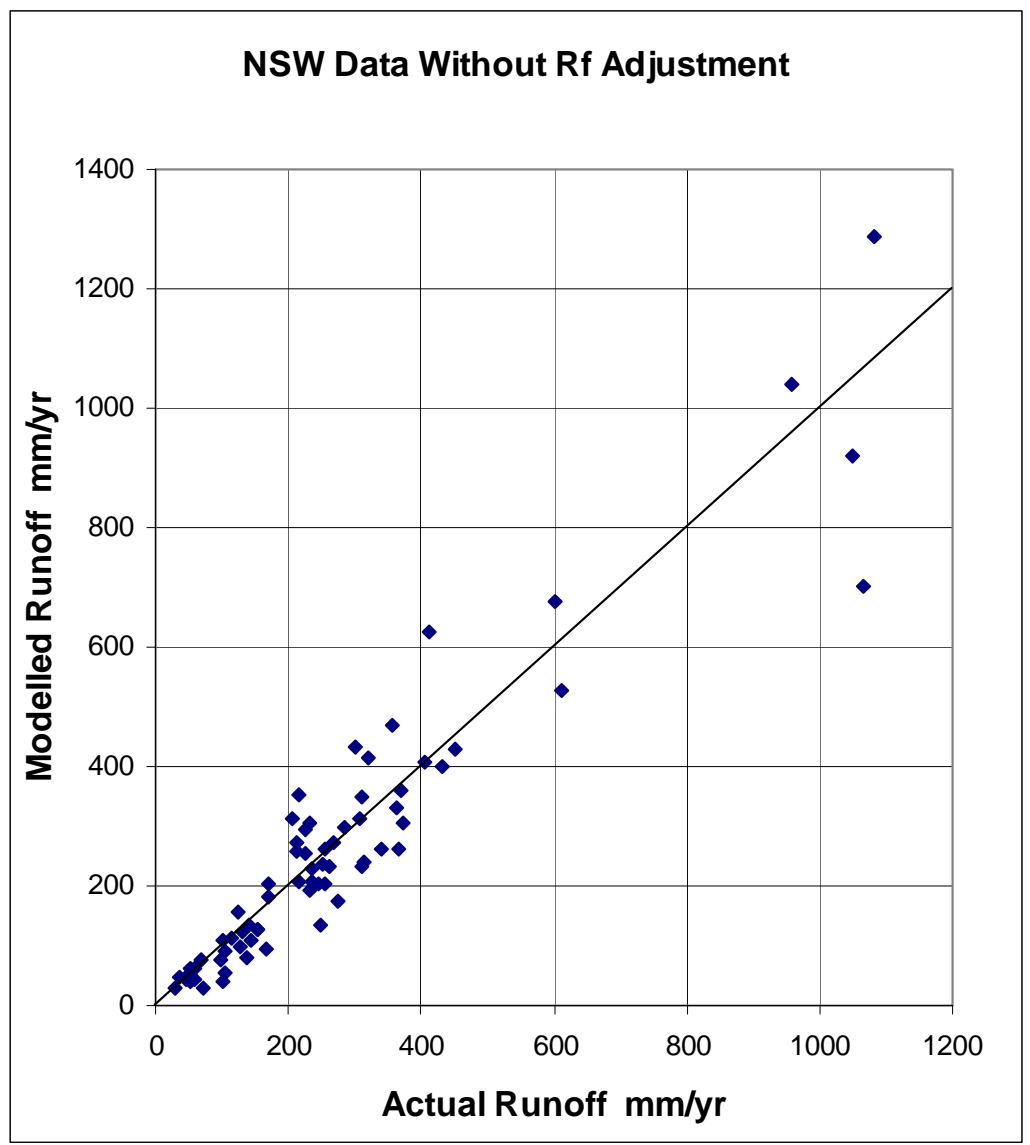

Figure 10 Comparison of observed and modeled runoff on 70 catchments in New South Wales with a single set of parameters - no adjustment of rainfall.

The large number of catchments and wide geographic spread prompted a study of variation among the 17 river basins that contain the 70 catchments. Two of the basins contained 10 catchments, and two other contained 6 catchments. These were enough to look at calibrations on sub-sets of the 70 catchments within individual river basins. Eventually, calibrations were made on catchments in all 17 basins. The main calibration was of the sole runoff generating parameter, i.e. the surface storage capacity. The calibrated values of this parameter are shown in Table 5.

Table 5 Calibrated surface storage capacities on groups of catchments in 17 river basins in New South Wales

\begin{tabular}{|c|c|c|c|}
\hline \multicolumn{2}{|c|}{ Basin } & N & $\begin{array}{c}\text { Storage } \\
\text { Capacity mm }\end{array}$ \\
\hline No & Name & & 145 \\
\hline 210 & Hunter & 10 & 105 \\
\hline 204 & Clarence & 10 & 155 \\
\hline 222 & Snowy & 6 & 135 \\
\hline 208 & Manning & 6 & 245 \\
\hline 205 & Bellinger & 5 & 155 \\
\hline 206 & Macleay & 4 & 140 \\
\hline 212 & Hawkesbury & 4 & 120 \\
\hline 203 & Richmond & 3 & 160 \\
\hline 211 & Macquarie/Tuggerah & 3 & \\
\hline
\end{tabular}




\begin{tabular}{|c|c|c|c|}
\hline 219 & Bega & 3 & 155 \\
\hline 220 & Towamba & 3 & 185 \\
\hline 221 & East Gippsland & 3 & 150 \\
\hline 207 & Hastings & 3 & 350 \\
\hline 209 & Karuah & 2 & 90 \\
\hline 218 & Tuross & 2 & 70 \\
\hline 201 & Tweed & 2 & 2000 \\
\hline 216 & Clyde & 1 & 125 \\
\hline
\end{tabular}

Note: $\mathrm{N}=$ number of catchments in basin

The four basins with either 10 or 6 catchments have a range of the calibrated surface storage capacity from $105 \mathrm{~mm}$ to $155 \mathrm{~mm}$. When the selection is extended to include basins with 3, 4 or 5 catchments, the range extended to capacities from $105 \mathrm{~mm}$ to $350 \mathrm{~mm}$. The basins with only 1 or 2 catchments showed such variation in surface storage capacity that it confirmed that such small numbers of catchments are almost guaranteed to give results of little practical use.

Table 6 shows the number of catchments in each range of surface storage capacities from the 13 river basins with 3 or more catchments in Table 5. There is a modal range centered on the value of $145 \mathrm{~mm}$ found from calibration of all 17 basins together. The concentration of values from the river basins with the most catchments obviously was a major factor determining the overall calibration of $145 \mathrm{~mm}$ in Table 4 . The very high value of $350 \mathrm{~mm}$ was from a river basin with only 3 catchments, and is evidence that a group of only 3 catchments can give results that are distinctly different from nearby basins with more catchments.

Table 6 Distribution of calibrated surface storage capacities in 13 river basins in New South Wales

\begin{tabular}{|c|c|}
\hline $\begin{array}{c}\text { Range of } \\
\text { Capacity mm }\end{array}$ & $\begin{array}{c}\text { No of } \\
\text { catchments }\end{array}$ \\
\hline $75-125$ & 2 \\
\hline $125-175$ & 8 \\
\hline $175-225$ & 1 \\
\hline $225-275$ & 1 \\
\hline $275-325$ & 0 \\
\hline $325-375$ & 1 \\
\hline
\end{tabular}

Unfortunately, the different calibrations in Table 5 cannot be related to catchment characteristics. Very small changes in estimation of catchment rainfall have a large effect on the calibration of the surface storage capacity that can account for all variations in calibration - see Figures 9 and 10. It will be necessary to determine areal rainfall over a catchment to a very small degree of precision before any effects of catchment characteristics could be estimated.

\section{DISCUSSION}


The method of calibration of the AWBM daily rainfall-runoff model that is developed in this paper is a first attempt to systematically allow for the effects of errors in the estimation of areal rainfall. The result of the new method is the production of a single set of parameter values that can be used to estimate runoff on all catchments in the group. This set of parameter values is an obvious choice to use for estimating runoff on ungauged catchments in the same region. The method is essentially a means of averaging the runoff generating characteristics of a group of gauged catchments for transfer to ungauged catchments in the same locality.

The use of rainfall adjustments factors as the main means of determining the single set of parameter values has no theoretical basis but produces practical results with potential for immediate use. The assumption that errors in the estimation of areal rainfall are normally distributed among a group of catchments is more reasonable than any obvious alternatives, but is not necessarily correct. This has potential for significant error when used with a small number of catchments, but increases in reliability with increase in the number of catchments. The results from the present study suggest that catchment numbers less than five are not reliable.

With adjustments of rainfall $\leq 15 \%$, the AWBM with a single set of parameter values can estimate average annual runoff in 65 catchments on the coast of New South Wales to any required degree of precision. The degree of precision is determined by how precise the rainfall adjustments are determined so that the calibrated value of the surface storage capacity matches that in the single set of parameter values. Hall and Barclay (1975) reviewed the estimation of areal rainfall for use in rainfall-runoff modelling. They state that errors of $10 \%-20 \%$ are common, and that, where strong wind effects or mountainous catchments are being considered, errors up to 60 per cent can be experienced. The results from the present study show that eliminating such errors would allow a single set of parameter values to be used with the AWBM to estimate runoff from a large number of catchments. The consequential result is that it will be impossible to determine the effects of catchment characteristics on runoff unless areal rainfall can be determined to a high level of precision. It seems certain that such a high level of precision does not exist in most of the data sets currently used in rainfall-runoff modelling.

The sole runoff generating parameter in the AWBM is the surface storage capacity. There are significant differences in the calibrated values of this parameter among the groups of catchments in different States of Australia, and also among subsets of the New South Wales data based on groups of catchments in individual river basins. Considering that runoff from most of the New South Wales catchments could be estimated with a single set of parameter values and small adjustments of rainfall, the significance of the differences among the basins is at best uncertain and at worst meaningless. The problem is that there is no way of distinguishing between the effects of errors in the estimation of areal rainfall and those due to differences in runoff generating catchment characteristics.

A great number of hydrological publications have documented evidence that show that runoff from forested catchments is less than from grassed catchments, all else being equal. Most of these studies have been on small catchments with direct comparison of measured runoff. It has been virtually impossible to demonstrate the same effects on large catchments. It seems that the inherent problems of estimating 
areal rainfall on catchments $\Rightarrow 100 \mathrm{~km}^{2}$ in area can overwhelm this most demonstrated effect of catchment characteristics on runoff.

\section{CONCLUSIONS}

The new method of calibration gives a single set of AWBM parameter values that can be used to estimate runoff from a group of catchments to any required degree of precision if small adjustments of input rainfall are made. The adjustments of areal rainfall in the order of $\leq 15 \%$ are within the accepted range of errors in estimating areal rainfalls for rainfall-runoff modelling on catchments $\geq 100 \mathrm{~km}^{2}$. The single set of parameter values can be used to estimate runoff from ungauged catchments in the same region as the gauged catchments used to determine the values. This provides a systematic method of averaging runoff generating parameters among the gauged catchments in a region for use on ungauged catchments. The method specifically allows for errors in the estimation of areal rainfalls in the catchments by normalizing the rainfall adjustments in the calibration process.

The results suggest that the current errors in estimation of areal rainfall in rainfallrunoff data sets are sufficient that determining the effects of catchment characteristics on runoff is virtually impossible. Small errors in rainfall data have a large effect on the calibrated values of model parameters. Until areal rainfall can be estimated with much greater precision than in current rainfall-runoff data sets, it will be impossible to determine the effects of catchment characteristics on runoff with any certainty. The difference in runoff between grassed and forested catchments has been demonstrated in many studies; however, the definitive studies have been on small catchments. The results do not appear in studies with data from large catchments. It seems that the errors in estimation of areal rainfall on large catchments are the reason why the results on small catchments cannot be replicated in the larger range of catchments.

The study has produced single sets of AWBM parameter values for groups of catchments in five States of Australia. The differences in the parameter values among the groups of catchments are tentative because the normalizing of rainfall adjustments to produce the values is an assumption without theoretical or empirical basis. Regardless, the method set out in the paper provides a systematic approach to producing a single set of parameter values from gauged catchments for use on ungauged catchments in the same region. The results in the paper are based on one rainfall-runoff model (AWBM). There is a need for the same approach to be tested on other models.

\section{REFERENCES}

Andréassian V., Hall, A., Chahinian, N. and Schaake, J. (2006). "Large sample basin experiments for hydrological model parameterization: Results of the model parameter experiment - MOPEX." Publication 307, International Association of Hydrological Sciences, Wallingford, Oxfordshire, UK.

Bates, B. C. (1994). "Regionalization of hydrologic data: a review." Cooperative Research Centre for Catchment Hydrology, Monash University, Melbourne, Australia. 
Blöschl, G. and Sivapalan, M. (1995). "Scale issues in hydrological modelling - a review." Hydrological Processes, 9(3-4), 251-290.

Boughton, W. C. (1996). "Detecting data errors in rainfall-runoff data sets." Report 96/2, Cooperative Research Centre for Catchment Hydrology, Monash University, 23 pp.

Boughton, W. C. (2004). "The Australian Water Balance Model." Environmental Modelling and Software, 19(10), 943-956.

Boughton, W. C. (2005). "Catchment water balance modelling in Australia 19602004.” Agricultural Water Management, 71,91-116.

Boughton, W. (2006). "Calibrations of a daily rainfall-runoff model with poor quality data." Environmental Modelling and Software, 21(8), 1114-1128.

Boughton, W. (2009). "New approach to calibration of the AWBM for use on ungauged catchments.” ASCE Jour. Hydrologic Engg., 14(6).

Boughton, W. and Chiew, F. (2003). "Calibrations of the ABM for use on ungauged catchments." Technical Report 03/15, CRC for Catchment Hydrology, Monash University, $37 \mathrm{pp}$.

Boughton, W. and Chiew, F. (2007). "Estimating runoff in ungauged catchments from rainfall, PET and the AWBM model." Environmental Modelling \& Software, 22(4), 476-487.

Chiew, F.H.S., Peel, M.C. and Western, A.W. (2002). "Application and testing of the simple rainfall-runoff model SIMHYD." In: Mathematical Models of Small Watershed Hydrology and Applications (Editors: V.P. Singh and D.K Frevert), Water Resources Publication, Littleton, Colorado, (ISBN 1-887201-35-1), pp. 335-367.

Hall, A. J. and Barclay, P. A. (1975). "Methods of determining areal rainfall from observed data." In: Chapman, T. G. and Dunin, F. X., "Prediction in Catchment Hydrology", Australian Academy of Science, Canberra, pp.47-57.

Haydon, S. and Delectic, A. (2009). "Model output uncertainty of a coupled pathogen indicator- hydrologic catchment model due to input data uncertainty." Environmental Modelling \& Software, 24(3), 322-328.

Jeffrey, S. J., Carter, J. O., Moodie, K. B. and Beswick, A. R. (2001). "Using spatial interpolation to construct a comprehensive archive of Australian climate data." Environmental Modelling \& Software, 16(4), pp.309-330.

Kokkonen, T. S., Jakeman, A. J., Youg, P. C. and Koivusalo, H., J. (2003). "Predicting daily flows in ungauged catchments: model regionalization from catchments descriptors at the Coweeta Hydrologic Laboratory, North Carolina." Hydrological Processes, 17(11), 2219-2238. 
McIntyre, N. and Al-Qurashi, A., (2009). "Performance of 10 rainfall-runoff models applied to an arid catchment in Oman." Environmental Modelling and Software, 24(6), 726-738.

Merz, R., Piock-Ellena, U., Blöschl, G. and Gutknecht, D. (1999). "Seasonality of flood processes in Austria." In: Hydrological extremes: understanding, predicting, mitigating (Ed. by L. Gottschalk, J. C. Olivry, D. Reed and D. Rosbjerg), Proc. Birmingham Symposium, July 1990, Public. 255, International Association of Hydrological Sciences, Wallingford, Oxfordshire, UK.

Merz, R. and Blöschl, G. (2004). "Regionalization of catchment model parameters." Journal of Hydrology, 287(1-4), 95-123.

Merz, R., Blöschl, G. and Parajka, J. (2006). "Regionalization methods in rainfallrunoff modelling using large catchment samples." In: Andréassian, V., Hall, A., Chahinian, N. and Schaake, J. (Eds.) 'Large sample basin experiments for hydrological model parameterization: Results of the model parameter experiment MOPEX', IAHS Publ. 307, pp.117-125.

Nathan, R. J. and McMahon, T. A. (1990). "Identification of homogeneous regions for the purpose of regionalization." Journal of Hydrology, 121(1-4), 217-238.

Peel, M.C., Chiew, F.H.S., Western, A.W. and McMahon, T.A. (2001). "Extension of Unimpaired Monthly Streamflow Data and Regionalisation of Parameter Values to Estimate Streamflow in Ungauged Catchments." Report prepared for the National Land and Water Resources Audit, In http://audit.ea.gov.au/anra/water/docs/national/streamflow/streamflow.pdf

Sefton, C. E. and Howarth, S. M. (1998). "Relationships between dynamic response characteristics and physical descriptors of catchments in England and Wales." Journal of Hydrology, 211(1-4), 1-16.

Seibert, J. (1999). "Regionalization of parameters for a conceptual rainfall-runoff model.” Agricultural and Forest Meteorology, 98-99, 279-293.

Singh, V. P. and Woolhiser, D. A., 2002. Mathematical modelling of watershed hydrology. ASCE Jour. of Hydrologic Engineering, 7(4), 270-292.

Yu, P. S. and Yang, T. C. (2000). "Using synthetic flow duration curves for rainfallrunoff model calibration at ungauged sites." Hydrological Processes, 14(1), 117-133. 